\title{
Features of structural transformations of HCP metallic Ti nanowires using Cleri-Rosato potential at low temperature
}

\author{
M.M. Aish ${ }^{1,2, \dagger}$ M.D. Starostenkov \\ ${ }^{\dagger}$ mohamedeash2@yahoo.com \\ ${ }^{1}$ Menoufia University, Gamal Abd El-Nasir, Shebeen El-Kom, 32511, Menoufia, Egypt \\ ${ }^{2}$ I.I. Polzunov Altai State Technical University, Lenin st. 46, 656038, Barnaul, Russia
}

\begin{abstract}
A molecular dynamics simulation of plastic deformation under uniaxial tensile strain for hexagonal close-packed Ti single crystals is performed to clarify the dislocation behavior. Simulations are performed using tight-binding model (the CleriRosato potentials). A computer experiment is performed at a temperature of $10 \mathrm{~K}$. The diagrams of the stored energy obtained at differrent times by the molecular dynamics simulations of the tensiled metallic Ti nanowires specimens show a rapid increase in stress up to a maximum followed by a gradual drop to zero at the ductile fracture of the specimen. The feature of deformation energy can be divided into three regions: quasi-elastic, plastic and failure. The nature of deformation, slipping, twinning and necking were studied. Stress decreases with the volume increase and the breaking position increase. The results showed that breaking position dependent on the nanowire length. Thus, it appears that Cleri-Rosato potentials can give good representation for the deformation behavior of hexagonal close-packed metallic Ti nanowires. The temperature dependence of the calculated Young's modulus is quite similar to the experimental results.
\end{abstract}

Keywords: molecular dynamics, uniaxial tension, Cleri-Rosato, nanowires, tight-binding and failure.

\section{Особенности структурных превращений ГПУ титановых нановолокон при низкой температуре, используя потенциал Клери-Розато}

\author{
Айш М.M. ${ }^{1,2 \dagger}$, Старостенков М.Д. ${ }^{2}$ \\ ${ }^{\dagger}$ mohamedeash2@yahoo.com
}

${ }^{1}$ Менуфийский университет, 32511, Менуфия, Египет

${ }^{2}$ Алтайский государственный технический университет им. И.И. Ползунова, ул. Ленина 46, 656038, Барнаул, Россия

Молекулярно-динамическое моделирование (МД) деформации нановолокон при одноосном растяжении для ГПУ простого кристалла Ті реализовано для выяснения зависимости деформационного поведения нановолокон от растяжения. Моделирование выполнено с использованием модели сильной связи (потенциал Клери-Розато). Компьютерный эксперимент выполнялся при температуре $10 \mathrm{~K}$. Диаграммы запасенной энергии, полученные в различное время с помощью МД моделирования для образцов металлических Ті нановолокон, подвергнутых растяжению, показали быстрое увеличение напряжения до максимума с последующим постепенным падением до нуля, когда образец терпит пластическое разрушение. Особенности в изменении запасенной энергии деформации можно разделить на три области: квазиупругую, пластическую и разрушение. Эти преобразования характеризуются различными структурными особенностями, что проявляется в характере изменения кривой зависимости запасенной энергии деформации и появлении различных типов структурных дефектов.

Ключевые слова: молекулярная динамика, одноосное растяжение, Клери-Розато, нановолокна, сильная связь, разрушение. 


\section{Introduction}

Currently, a wide range of metals with crystalline type hexagonal close-packed (HCP) lattice. The ability of metals to form alloys with specific physical and mechanical properties is crucial for the technical application. Because of the strong anisotropy of the structure, defects in HCP metals and alloys have a number of features that is of great interest to them and requires detailed consideration.

The description of interactions between atoms is very crucial in any atomistic simulation, ranging from firstprinciples electronic structure calculations to semi-empirical methods. Ab-initio techniques are superior, accurate and can supply information on diffusion barriers, but they are limited by high computational costs. They are therefore used for relatively short time scales and small systems. In order to simulate longer time scales and larger systems parameterbased empirical methods such as the many-body potentials of the embedded-atom method (EAM) [1, 2], Finnis-Sinclair [3] potentials and the second-moment approximation (SMA) of the tight-binding (TB) method [4-9] are found to be very efficient. The semi-empirical methods, although less accurate, are very fast and able to simulate the dynamical character of diffusion and reveal different elementary processes (e.g., hopping or adatom-surface exchange). In particular, the TB-SMA expression [7-9] of the total energy of a metallic system is based on a small set of adjustable parameters, which can be determined by adjusting to experimental data $[9,10]$ or ab-initio results [1,10-13]. A three-dimensional nanowire with rectangular cross-section cut from single-crystal bulk is simulated. Fig. 1 shows the MD simulation model of metallic nanowires generated from a bulk HCP metallic crystal.

Aish et al. [13 - 17] have studied the mechanical properties of Ni nanowires where they concluded that the mechanical properties of Ni nanowires are highly dependent on the size, shape as well as the atomic vacancies in the nanowire.

The article discusses the results of MD simulation to HCP phase in metallic nanowires, obtained using the interatomic potential of strong coupling (tight-binding).

Table 1 gives the dimensions of the HCP nanowire, rate of loading, temperature, etc. Cell parameters are denoted by $a_{0}$ and $c_{0}$, where $a_{0}$ - the interatomic distance in the layer, $c_{0}$ - the distance between the first and third layers. The MD simulations were carried out till separation occurs in the tensile specimen. Fig. 1. Shows Model of hexagonal Ti nanowire with hcp structure, (a) and (b) 3D view, (c) and (d) the atomic configuration on the base of the nanowire with orientation [0001] plane. The MD simulations were carried out till separation occurs in the tensile specimen.

\section{Results and discussion}

Since the feature of deformation and fracture of HCP Ti nanowires are of main interest in this work (Table 1). The specimen used for the [0001] direction is a nanowire of $18 a_{0} \times 18 a_{0} \times 18 c_{0}$, long, where. The total number of atoms used in the simulations equal 5832 according on the crystal structure. The crystal was set-up with a hexagonal orientation and the uniaxial tensile force was applied along the [0001] direction. The nature of deformation, slipping, twinning and necking were studied.

The strength of Ti was estimated to be $=16.3 \mathrm{GPa}$.

\subsection{Three stages deformation}

The experiments were obtained plots of the stored energy of deformation at various times, reflecting the processes in the HCP nanowires during deformation.

There are three stages of deformation: the quasi-elastic deformation (I), plastic deformation (II), as can seen from the figure the flow occurs at the end of second stage of deformation, and the breaking (failure) (III).

In the first stage there was almost linear increase in stored energy. The initial stage quasi-elastic area there is only relative displacement of atoms and there are no defects. Therefore, in this region the energy stored varies periodically. This stage is completed at $10 \mathrm{Ps}$, for $\mathrm{Ti}-18 a_{0} \times 18 a_{0} \times 18 c_{0}$. The sharp fall takes place only at the point of transition from the first to second stages of deformation (Fig. 2).

Analysis of the graphs in Fig. 2 shows that the duration of the plastic deformation step is $480 \mathrm{Ps}$, for Ti $-18 a_{0} \times 18 a_{0} \times 18 c_{0}$.

The value of the stored energy at the peak of deformation schedule at the end of the first stage for the reduced nanowire equal $0.021 \mathrm{eV} /$ atom. The levels of stored energy at the end of the plastic deformation steps are equals $0.114 \mathrm{eV} /$ atom. The neck of the HCP Ti nanowire forms after the slips happened,

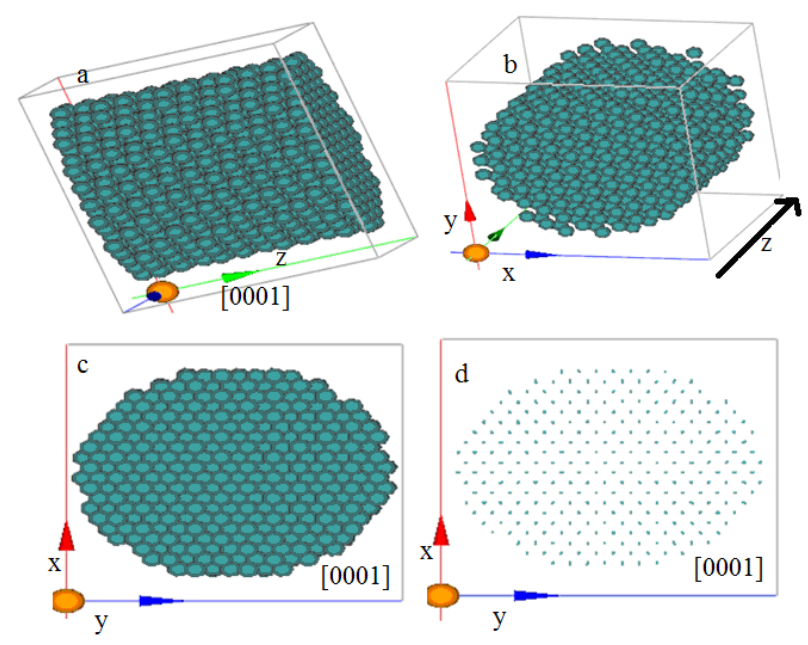

Fig. 1. Model of hexagonal nanowire with hcp structure, (a) and (b) $3 \mathrm{D}$ view, (c) and (d) the atomic configuration on the base of the nanowire with orientation [0001] plane.

Table 1. Parameters used in this work for Ti nanowireof uniaxial tensile loading.

\begin{tabular}{|l|l|}
\hline Configuration & 3-D \\
\hline Ab-initia Potential used & Cleri-Rosato \\
\hline $\begin{array}{l}\text { HCP Ti nanowire } \\
\text { dimensions }\end{array}$ & $\begin{array}{l}18 a_{0} \times 18 a_{0} \times 18 c_{0}, a_{0} \text { and } c_{0}- \\
\text { lattice constants }\end{array}$ \\
\hline Tensile loading condition & Uni-axial \\
\hline Speed of simulation & $200 \mathrm{~m} / \mathrm{s}$ \\
\hline Temperature & $10 \mathrm{~K}$ \\
\hline
\end{tabular}


and the deformations have been carried mainly through the elongation of the neck. Through further analysis, we find that the last stage of plastic deformation of the neck is formed; deformation develops mainly due to the reconstruction and rebuilding of the neck area. Outside this area, the HCP nanowires ordered structure is retained and there are significant changes. Beyond the neck region, atomic structures have no significant changes. The atomic rearrangements in the neck region induce the zigzag increase-decrease in stored energy with time. The atoms, close to the narrowest region of the neck, are highly disordered.

At the point of breaking, we observe a one-atom thick. With further pulling of the HCP Ti nanowires, the bond between the two atoms lying in the one-atom breaks and then the rupture happens. As can be expected the ultimate strength of Titanium nanowire was estimated to be $18.2 \mathrm{GPa}$ for $\mathrm{Ti}-18 a_{0} \times 18 a_{0} \times 18 c_{0}$ at $10 \mathrm{~K}$.

\subsection{On the nature of deformation and fracture under tensile loading}

The MD simulation plots of the [0001] direction of the tensile deformation at various stages of uniaxial loading are shown in Fig. 3 is for the HCP Ti material. It may be noted that the discussion of the results presented here is based not only on the MD simulation plots of the various stages presented here but also on the detailed study of the results of the process which was accomplished using a special computer program developed for this purpose [17]. For the HCP materials after relaxation, the specimens were found to be slightly compressed due to internal forces.

Fig. 3 shows a small compressive bulge of the specimen after the relaxation at time 10 Ps for the case of Ti. Initially, dislocations at $35 \mathrm{~K}$ were observed in the animation for the case of $\mathrm{Ti}$ but due to the high disorder, further dislocation propagation was difficult to observe at $35 \mathrm{ps}$.

As the HCP Ti nanowires was extended, bridging of the top and bottom portions of the crystal by a disordered neck of constantly decreasing diameter can be seen from times 100 Ps to the breaking time which take place at $500 \mathrm{Ps}$ for $\mathrm{Ti}$ nanowire.

Based on the results, as well as the MD simulations at various stages of deformation (Fig. 4), the strain to fracture was observed to the HCP Ti nanowire. In the case of HCP Ti nanowire, the work nanowires were disordered from the early stages of necking till the end. Consequently, it was possible to observe all structural changes in the crystal. The disorder was observed to extend throughout the entire length of the work material.

\subsection{The radial distribution of atoms and the fraction of atoms with displacement for Ti crystal}

In this part of the work the radial distribution of atoms has been studied for Ti nanowire. The graphs characterize the distribution of atoms in a crystal relative to each other. The feature of the algorithm produced radial distribution schedule is a necessity after relaxation of the calculated block by ultrafast cooling to $0 \mathrm{~K}$, at the start of the experiment (Fig. 4a). Otherwise, at the end of the experiment (500 Ps) the graph of radial distribution has been studied carefully (Fig. 4b).

Another important point in this work is to study a graph of the fraction of atoms in the displacement. It is possible to estimate the fraction of atoms at different displacement of the particle $(F s, \%)$ using the simple relation,

$$
\text { Fs }=N_{d} / N \times 100 \text {, }
$$

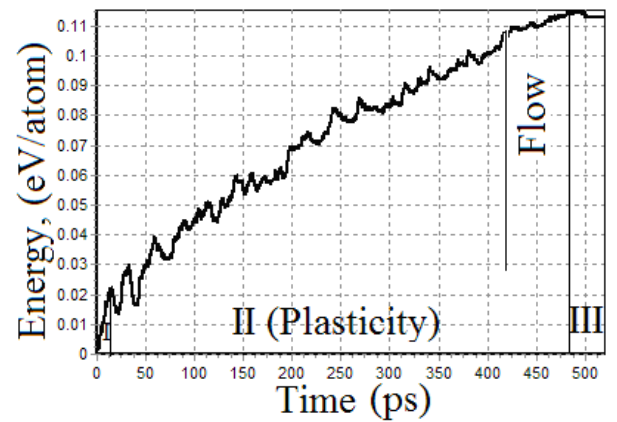

Fig. 2. The dependence of the energy stored by the deformation time of the experiment at $10 \mathrm{~K}$ at various time of uniaxial loading for $\mathrm{Ti}$ nanowire.

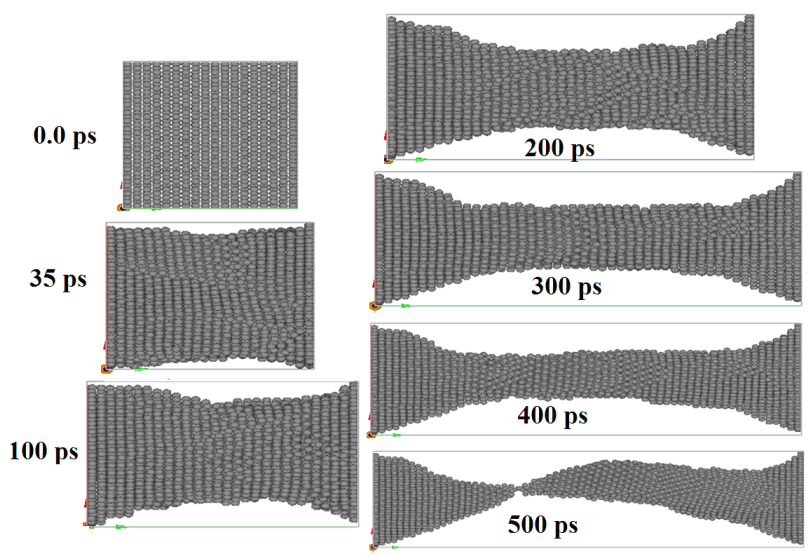

Fig. 3. MD simulation plots of the $X Z$ direction of a tensile specimen at various time of uniaxial loading for Ti nanowire in plane [1010] right and in plane [0110] left.
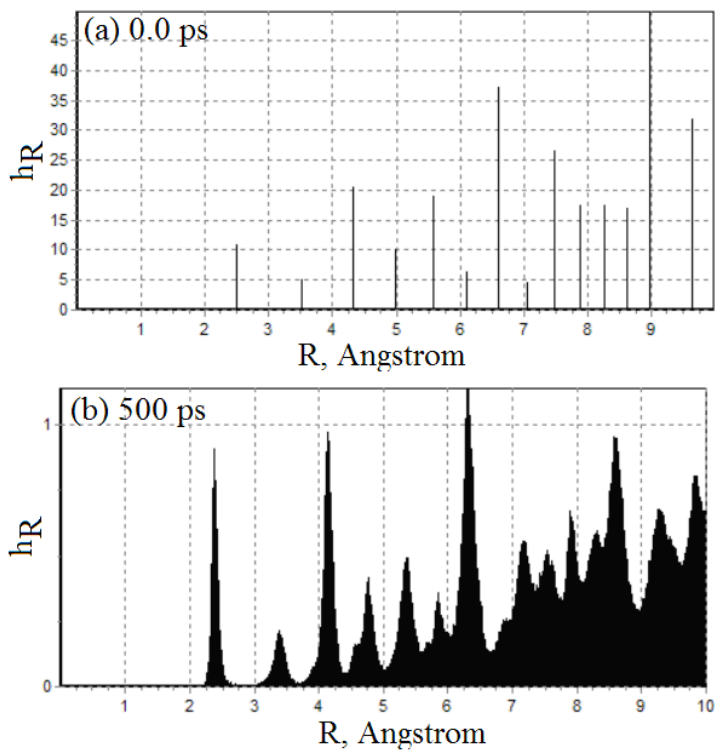

Fig. 4. The radial distribution of Ti nanowire at zero ps (a) and $500 \mathrm{ps}(\mathrm{b})$. 
where $N_{d}, N$ is the shifted atoms and the total number of atoms, respectively, in the Ti Crystal. The variation of the fraction of atoms with Shift of atoms is shown in Fig. 5. We see that the fraction of atoms becomes more than $45 \%$ when the displacement equal 50 Angstrom.

At 300 ps in the second stage of deformation was formed parts with different displacement direction in nanowires with substructural units (SB-1, SB-2, SB-3, SB-4, SB-6 and SB7 in Fig. 6a). The boundaries of substructural units represented by packaging defects. With increasing strain occurred rotation at the end of second second stage of deformation of the nanowires with formation substructure unit (SB-1, SB-2, SB-3 and SB-8 in Fig. 6b). Substructural blocks, formed by turning portions on $\mathrm{Ti}$ nanowires, have been oriented towards each other not parallel.

\subsection{The force on the basis of Ti crystal}

The force on the six basis of Ti crystal shown in Fig. 7 can accurately estimated the defects in the block and internal distribution of local stresses. The force calculated for each atom and for each atomic plane, constructed schedule of distribution of forces in each plane of Ti crystal using numerical analysis.

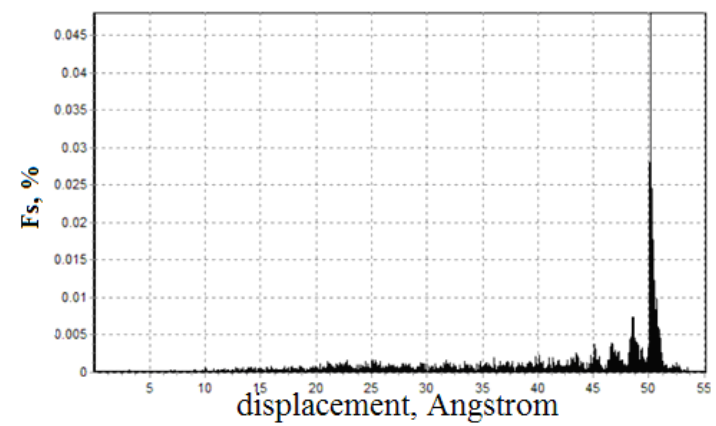

Fig. 5. Plot of the displacement of atoms vs. the percentage of toms at 500 ps. The calculation of the percentage of atoms is made on the basis of (1) and is valid for metallic Ti.

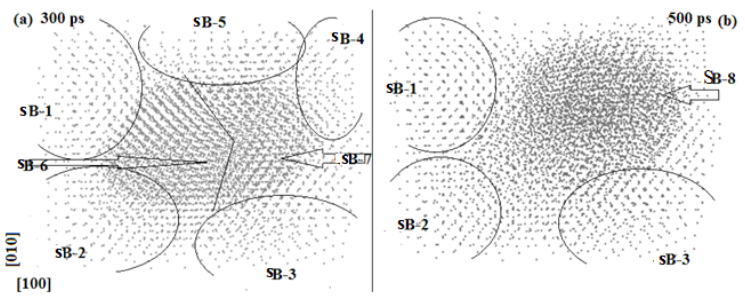

Fig. 6. Atoms in (111) plane in Ti nanowires in the direction of $<110>$ at $10 \mathrm{~K}$ at $300 \mathrm{ps}$ (a) and $500 \mathrm{ps}$ (b).

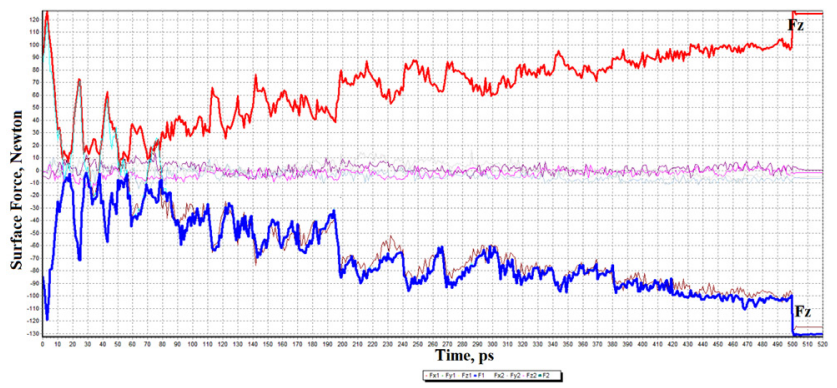

Fig. 7. Plots of the force on the six basis of a tensile specimen at various time of uniaxial loading for $\mathrm{Ti}-18 \times 18 \times 18$ nanowire.
The MD simulation plots of the forces for each atomic plane on the three directions for the HCP material Ti nanowire at 500 ps of the tensile specimens at various planes of system are shown in Figs. 8-10 are for the HCP material Ti $O X$, $O Y$ and $O Z$ directions respectively. It may be noted that the discussion of the results presented here is based not only on the MD simulation plots of the forces for each atomic plane presented here but also on the detailed study of the animation of the process which was accomplished using a special computer program developed for this purpose [13-17].

Based on the animations, as well as the MD simulations at various atomic plane (Figs. $8-10$ ), the forces for each atomic plane was observed to the HCP Ti nanowire. This can be observed by comparing Figs. 8-10 which shows a pictorial view of the variations in the forces for each atomic plane of various directions in Ti crystal.

According to Fig. 10 the maximum force $(F y=1200 \mathrm{~N})$ takes place in the $5^{\text {th }}$ atomic plane and the minimum value $(F z=-440 \mathrm{~N})$ takes place in the $7^{\text {th }}$ atomic plane on $O Z$ direction for Ti nanowire at $500 \mathrm{ps}$.

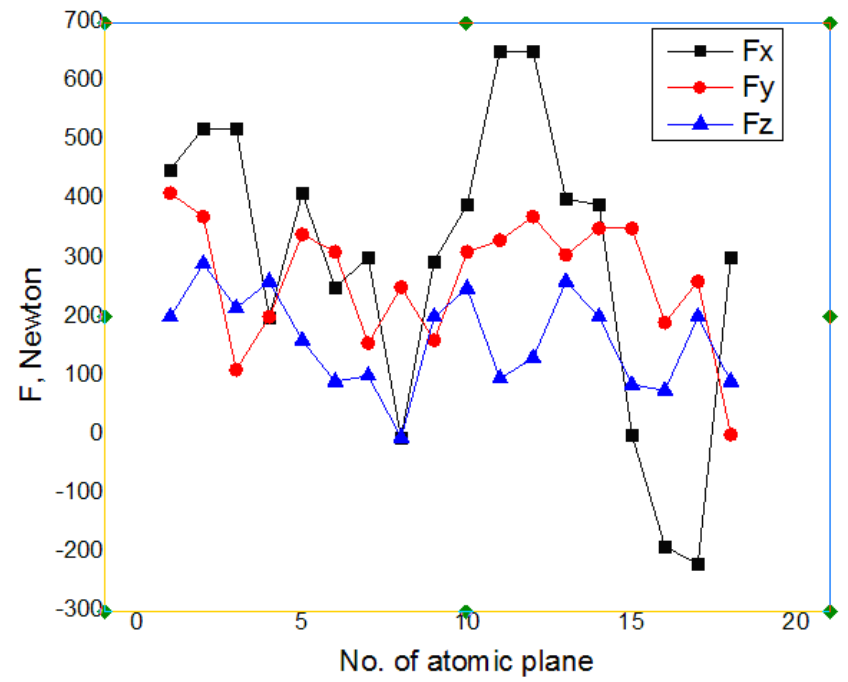

Fig. 8. The forces for each atomic plane on $O X$ direction for $\mathrm{Ti}$ nanowire at $500 \mathrm{ps}$.

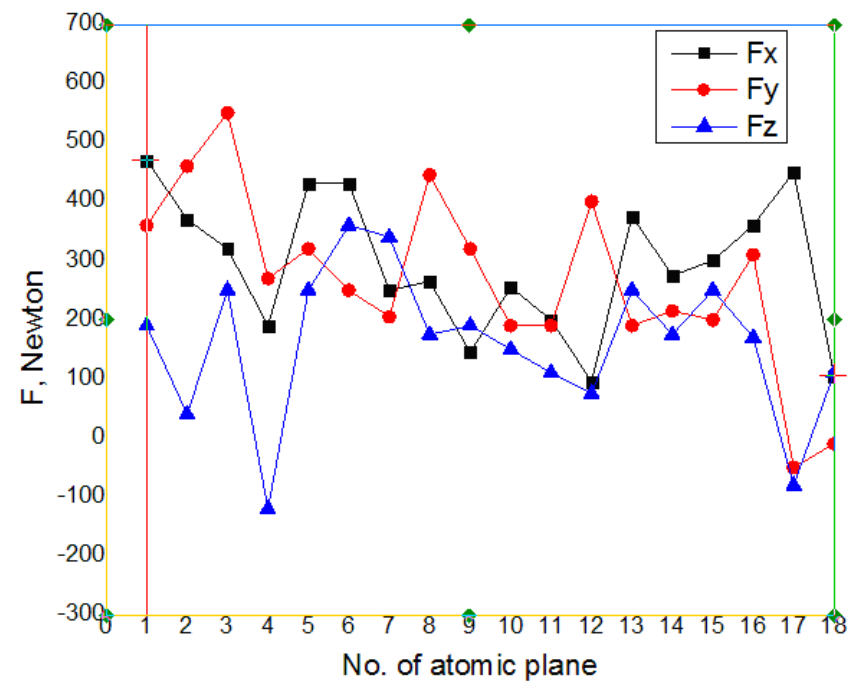

Fig. 9. The forces for each atomic plane on $O Y$ direction for $\mathrm{Ti}$ nanowire at $500 \mathrm{ps}$. 


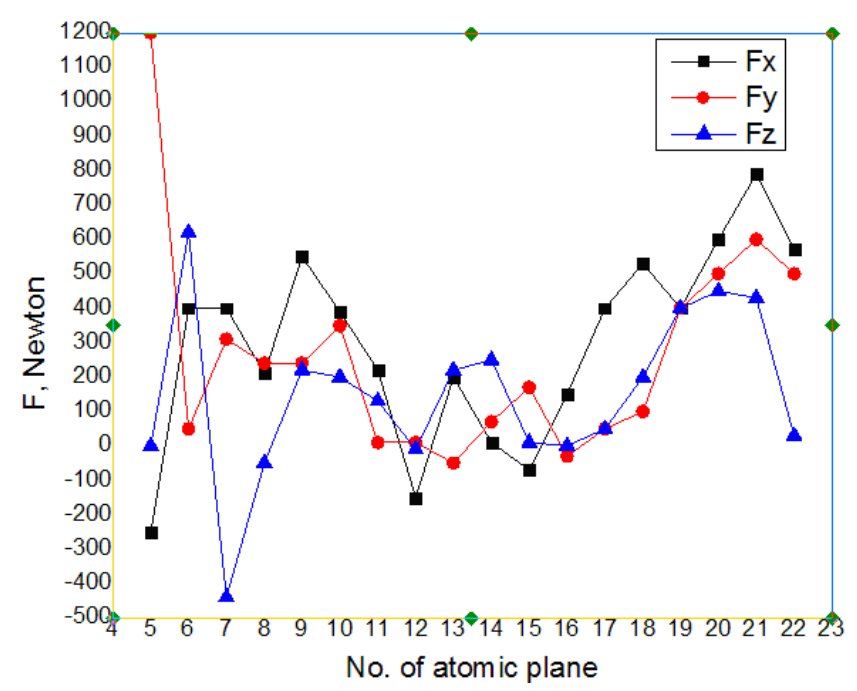

Fig. 10. The forces for each atomic plane on $\mathrm{OZ}$ direction for $\mathrm{Ti}$ nanowire at $500 \mathrm{ps}$.

\section{Conclusion}

Dynamics of structural transformation in single-crystal hexagonal metals, $\mathrm{HCP} \mathrm{Ti}-18 \times 18 \times 18$ when subjected to a uniaxial tension at $10 \mathrm{~K}$ have been studied using $\mathrm{MD}$ simulation. Atomic configurations and strain energy have been characterized during stored energy application. These quantities revealed three distinct structural transformations that take place during tensile deformation, namely: the quasi-elastic, plastic and fracture. These transformations are characterized by distinct structural features as manifested by the strain energy curve and the appearance of structural defects.

The stored energy diagrams at various time obtained from the MD simulation of the tensile specimens show a rapid increase in stress up to the maximum followed by a gradual drop to zero when the specimen fails by ductile fracture.

Failure of the HCP Ti nanowire due to void formation, nature of stress for surface atoms in $X Y$ lane, the radial distribution of atoms and the fraction of atoms with displacement for Ti crystal, the forces for each atomic plane on all directions and the force on the six basis of Ti crystal is observed using Cleri-Rosato Potential.

HCP Ti nanowires, considerable disorder in the XOY section of the Ti crystal was observed during the early stages of loading. Further loading resulted in the disorder spreading through the entire length of the HCP Ti nanowire.

Cleri-Rosato potential shows good agreement with other works studied the ultimate strength and the strain to failure for the HCP metallic nanowires.

Acknowledgments. The study was funded by RFBR according to the research project No.15-48-04127 r_siberia_a and within the science project No.166 of the Board of education and science RF program "Forming governmental tasks for the high education institutions, particularly science experimentations".

\section{References}

1. F. Ercolessi and J.B. Adams. Europhys. Lett. 26, 583 (1994).

2. Y. Mishin, D. Farkas, M. J. Mehl and D. A. Papaconstantopoulos. Phys. Rev. B 59, 3393 (1999).

3. Y. Mishin, M.J. Mehl, D.A. Papaconstantopoulosm, A. F. Voter and J. D. Kress. Phys. Rev. B 63, 224106 (2001).

4. Y. Mishin, M.J. Mehl and D. A. Papaconstantopoulos. Phys. Rev. B 65, 224114 (2002).

5. R. R. Zope and Y. Mishin. Phys. Rev. B 68, 024102 (2003).

6. A. Strachan, T. Cagin, O. Gülseren, S. Mukherjee, R. E. Cohen and W. A. Goddard. Model. Simul. Mater. Sci. Eng. 12, S445 (2004).

7. Y. Mishin, M. J. Mehl and D. A. Papaconstantopoulos. Acta Mater. 53, 4029 (2005).

8. Y. Mishin and A. Y. Lozovoi. Acta Mater. 54, 5013 (2006).

9. H. Chamati, N. Papanicolaou, Y. Mishin and D. A. Papaconstantopoulos. Surf. Sci. 600, 1793 (2006).

10. I. J. Robertson, V. Heine and M. C. Payne. Phys. Rev. Lett. 70, 1944 (1993).

11. S. L. Frederiksen, K.W. Jacobsen, K.S. Brown and J. P. Sethna. Phys. Rev. Lett. 93, 165501 (2004).

12. F. Cleri and V. Rosato. Phys. Rev. B 48, 22 (1993).

13. Mohammed Aish and Mikhail Starostenkov. AIP Conf. Proc. 1698, 040006 (2016).

14. M.M. Aish, M.D. Starostenkov. Materials Physics and Mechanics. 24 (2), 139 (2015).

15. M. D. Starostenkov, M.M. Aish. Materials Physics and Mechanics (2014) 21 (1), 1 (2014).

16. M.D. Starostenkov, M.M. Aish. Advanced Materials Research. 1013, 242 (2014).

17. M.M. Aish, M.D. Starostenkov. Materials Physics and Mechanics. 18 (1), 53 (2013). 